Notices of the Royal Astronomical Society, 118, 125, 1958). Their work was based on a selection of the available data, including only the more distant stars, for which the velocities should show galactic rotation effects. The rotation is usually described by the Oort constant $A$; the value of $A$ has been the subject of some controversy. Analysing their data in several ways, Feast and Thackeray obtain for $A$ the mean value $17.5 \pm 1.5 \mathrm{~km}$./ $/ \mathrm{sec}$./kiloparsec. The new results do not support the lower values of $A$ obtained in some earlier determinations. Two partly independent methods were used to derive a value of the distance from the Sun to the galactic centre; the most probable value is 8.9 kiloparsecs. A value of 0.5 for the ratio of the axes of the velocity ellipsoid appears to be appropriate for distant $B$-type stars. The final section of the paper by Feast and Thackeray is devoted to a discussion of the variation of the angular velocity $\omega(R)$ of the Galaxy as a function of the distance $R$ from the galactic centre. The results are in general agreement with the curve derived from Schmidt's model of the Galaxy, itself based on $21-\mathrm{cm}$. radio observations. $\omega^{\prime \prime}(R)$ definitely appears to be positive rather than negative. A negative value, obtained in some earlier investigations, is very unlikely on general dynamical grounds.

\section{Australian Biochemical Society}

THE Australian Biochemical Society held its third annual general meeting in the Medical School, University of Adelaide, during August 18-20. At this meeting fifty-three papers were presented, and the second annual lecture of the Society was given by Mr. Hedley Marston, on "The Biochemical Function of Cobalt". The present membership is 280 , and this year's president is Prof. R. K. Morton, of the Waite Institute, Adelaide. The honorary secretary is Dr. F. D. Collins, Department of Biochemistry, University of Melbourne.

\section{Welsh Soils Discussion Group}

UNDER the auspices of the Welsh Plant Breeding Station and the Departments of Agricultural Chemistry, Geography and Geology in the University College of Wales, Aberystwyth, a Soils Discussion Group has been formed, which held its first meeting on October 29. Some of the members of the Group are members of the British Society of Soil Science, which has recently lent its support to the formation of local groups to concentrate on soil studies in their local areas. Some thirty members attended the first meeting, including Dr. Alex Muir, director of the Soil Survey of England and Wales, and some members of the staff of the Departments of Agricultural Chemistry at the University College of North Wales, Bangor, of the Nature Conservancy (North Wales), of the Forestry Commission (Aberystwyth) and of the National Agricultural Advisory Service (Trawscoed). The first meeting was addressed by Dr. Nicholas Rast (Geology Department, Aberystwyth) on "Geochemistry in the Service of the Soil". The second meeting of the Group will be held in Aberystwyth at the Department of Geography on February 4, when Mr. James A. Taylor (Department of Geography) will lecture on "Slope, Climate and Soil". A third meeting will be held on April 22, when Dr. Rice Williams (Trawscoed) will introduce the subject "The Soils of the Aberystwyth Area". Further information can be obtained from J. A. Taylor, Department of Geography, University College of Wales, Aberystwyth.

\section{U.S. National Research Council Conference on Fracture}

THE National Academy of Sciences-National Research Council is organizing a seminar on "The Atomic Mechanisms of Fracture" to be held in Cambridge, Massachusetts, during April 12-14, 1959 , to discuss the following topics: theoretical aspects of fracture; cleavage ; crystalline and noncrystalline fracture; fatigue and ductile fracture; high-temperature fracture. The conference is being sponsored jointly by the National Science Foundation, Office of Naval Research, Air Force Office of Scientific Research, and the National Academy of Sciences National Research Council. Further information may be obtained from Dr. B. L. Averbach, chairman, or Dr. D. K. Felbeck, secretary, Conference on Fracture, National Academy of Sciences - National Research Council, Washington, D.C.

\section{Announcements}

Dr. M. L. M. SAlGado, soil chemist and acting director, has been appointed permanent director of the Coconut Research Institute of Ceylon.

THE following were recently elected to office in the Mineralogical Society : President, Prof. C. E. Tilley ; Vice-Presidents, Prof. L. R. Wager and Dr. A. K. Wells; Treasurer, Prof. J. H. Taylor ; General Secretary, Dr. G. F. Claringbull ; Foreign Secretary, Dr. L. J. Spencer; Editors of the Journal and Abstracts, Dr. M. H. Hey and Dr. N. F. M. Henry.

The Geological Society of London has announced the award of R. H. Worth Prizes as follows: to Mr. E. W. J. Moore, in recognition of his work on the goniatite succession of the Carboniferous rocks of the north of England and Ireland; and to Mr. C. W. Wright, in recognition of his researches on the stratigraphy and faunas of the English Cretaceous rocks, and especially on the Cretaceous Ammonoidea.

AN informal discussion on "Relaxation Processes" will be held under the auspices of the Faraday Society in the Department of Chemical Engineering of the Imperial College of Science and Technology on November 27. An introduction by Prof. A. R. Ubbelohde will be followed by contributions by Prof. C. J. F. Bottcher (Leyden) on dielectric relaxation; Dr. Vera Daniel (Electrical Research Association) on dielectric relaxation in crystals containing hydrogen bonds ; Mr. W. Reddish (Imperial Chemical Industries, Ltd., Plastics Division) on relaxation in high polymers in the solid state; and Dr. J. Lamb (Imperial College) on ultrasonic relaxation in liquids. Further information can be obtained from Dr. J. C. McCoubrey, Department of Chemical Engineering, Imperial College of Science and Technology, London, S.W.7.

IN Nature of October 18, p. 1060, the list of Waverley awards was printed; a special award was announced in the official list as being made to $\mathrm{Mr}$. M. D. Lilley. This was incorrect; the award was made to Miss M. D. Lilley, of Aplin and Barrett, Ltd.

ERratum. In the communication "Removal of Gases in High Vacuum Systems by Metal Abrasion", by M. E. Haine, E. W. R. Francis and R. N. Bloomer in Nature of October 4, p. 931, par. 2, line 7, for "litres/usec." read "litre microns per sec." ; the 'litre micron' is a unit of quantity of a gas where the volume of the gas is in 'litres', the pressure of the gas is in 'microns' ( $10^{-3} \mathrm{~mm}$. mercury). 